\title{
Delay in maternal near miss case and associated factors among women admitted in Felege Hiwot comprehensive specialized hospital, Northwest Ethiopia
}

Amsalu Worku Mekonnin ( $\square$ amsalework4@gmail.com )

Bahir Dar University https://orcid.org/0000-0002-5507-3229

Endalkachew Worku Mengesha

Bahir Dar University

Getu Dinku

Bahir Dar University

Research article

Keywords: Maternal near miss, severe maternal morbidity, Ethiopia

Posted Date: September 16th, 2019

DOl: https://doi.org/10.21203/rs.2.14439/v1

License: (c) (i) This work is licensed under a Creative Commons Attribution 4.0 International License.

Read Full License 


\section{Abstract}

Background: The current discrepancies in maternal mortality and near miss cases of high and low income countries are usually due to the differences in timely management of obstetric complications and the differences in time management comes up with idea of delay in receiving obstetric care. For each maternal death there will be 20 others that suffer as maternal near miss cases worldwide. This study aimed to assess delay of maternal near miss (MNM) and associated factors among women in Felege Hiwot Comprehensive Specialized Hospital (FHCSH), Northwest Ethiopia.

Methods: Cross sectional facility based study was conducted among 287 women who were managed as MNM from May 2018 to September 30, 2018. A checklist and structured questionnaire was used to retrieve information from the patient and her medical document. The collected data was cleaned, coded and entered for analysis. The results were presented in tables. Binary and multiple logistic regression analysis were calculated at $95 \% \mathrm{Cl}$.

Results: There were 2694 patients admitted in wards in the study period and proportion of maternal near miss was $10.65 \%$ with maternal near miss mortality ratio of 31.9 and mortality index of $3 \%$. From all maternal near misses studied $44.3 \%$ had first delay and $35 \%$ had second delay with $51.2 \%$ had third delay. Seventy four percent of them had at least one delay. Determinant factors identified were rural residence [AOR, 3.2 $\mathrm{P}=0.001$ ], distance more than $10 \mathrm{Kms}$ away from hospital [AOR, 2.18, $p=0.025$ ], lack of ambulance [AOR, 3.9 P=0.009] and lack of awareness on obstetric complications [AOR,27.9, $p=0.001$ ] which were statistically associated with any maternal delay.

Conclusion: Maternal near miss proportion is still high in study site and majority of them had at least one delay in receiving care which needs an intervention at community and low level health institutions.

\section{Background}

Maternal near miss is defined as a woman who survived of life threatening conditions during pregnancy and child birth or within 42 days of pregnancy termination irrespective of the site of pregnancy and receiving medical or surgical care.). A woman who survived of pregnancy related complications during pregnancy intrapartum or within 42 days of pregnancy termination having any of life threatening conditions as per the WHO criteria is labeled as MNM[1-4].

Over 1000 women still die every day from pregnancy related complications around the world and Low income countries are heavily affected by the burden of maternal deaths where it is a public health problem[5]. mortality is just the tip of iceberg; the base is to the tip of iceberg is MNM morbidity which remains undescribed[6].The are many MNM cases for every maternal death which ranges varies from 15 permanent disabilities to 100 acute episodes of morbidities [4]. Around 15\% all pregnant women develop potential life threatening complications that need skilled professionals and others may require major obstetric intervention to survive. According to United Nations Fund for Population Activity (UNFPA) report in 2011, for each maternal death there will be 20 others that suffer as maternal near miss cases 
worldwide and Ethiopia is one of the low income country with high maternal mortality ratio that showed improvement over the last two decades but still below the minimum MDG of maternal death reduction. According to the recent EDHS the mortality ratio of Ethiopia is 412 per 100000 live births [7-11]. Current differences in maternal near miss cases of high and low income countries is usually due to the differences in timely management of obstetric complications[12]. While clinical interventions and technologies may be available to manage obstetric emergencies, several factors may contribute to suboptimal outcomes, including: delay in diagnosis, outdated clinical protocols, inadequately trained staff, failure to employ sufficient medical and surgical staff and lack of essential medications, equipment, and supplies.

Although any intervention program must address all three delays to have any chance at sustainable, scalable success and in practice, it is crucial to address the third delay first, for it would be useless to facilitate access to a health facility if it was not available, well-staffed, well-equipped and providing good quality care $[12,13]$.

In multicenter population based research done in low income 7 countries over 2 years enrollment showed that $15 \%$ of women had a potential near miss event and $26.6 \%$ had maternal near miss with ratio of near miss to maternal death was 26 to 1 .In other study done in Uganda showed that MNM was $22.7 \%$ and severe preeclampsia and postpartum hemorrhage were common causes of MNM cases [13,14].

A national multicenter crossectional study on delays in receiving obstetric care and poor maternal outcomes in referral hospitals of Brazil showed that $53.8 \%$ of the cases had any type of delay and delay 1 , delay 2 and 3 rd delay models had a contribution of $10.2 \%, 34.6 \%$ and $25.7 \%$ respectively. This study also showed that $68.4 \%$ of MNM cases had any delay in receiving obstetric care [13].

In a facility based descriptive observational study on MNM done in South Africa showed that one or more factors causing a delay in accessing care were identified in 83\% of MNM cases with phase I and phase III being the most important barriers. The major important factors causing phase I delay were lack of knowledge of the problem (40\%) and inadequate antenatal care in $37 \%$ of MNM cases. Delay in patient admission, referral and treatment (37\%) and substandard care (36\%) were the problems as cause of phase III delay. The most important factors causing MNM were obstetric hemorrhage, hypertensive disorders of pregnancy, and medical and surgical conditions [14]. In a case control study done in Women's Health Hospital, Assiut University Egypt showed that nearly $50 \%$ of maternal near misses had two or more type's delays. Significantly associated factors with delay pattern identified in the study were financial problems, fear of maltreatment in health institutions, lack of awareness about obstetric complications, lack of antenatal care, lack of participation in decision making, negative attitude for health professionals and lack of blood and other study done in Mozambique obstetric hemorrhage (58\%) and eclampsia(35.5\%) were the commonest causes of MNM and $69.7 \%$ had delay 3 and lack of blood was from delay 3 factor identified[15, 16].

In crossectional study on maternal near misses in Amhara regional referral hospital in study period was $23.3 \%(95 \% \mathrm{Cl})$ and $90.4 \%$ of them were in critical condition on arrival. Among the identified maternal 
near miss cases $23.1 \%$ had organ dysfunction and $23.3 \%$ of them had severe complications. Uterine rupture contributed to maternal near miss cases is $27.66 \%$ [7].

The prevalence of MNM in Debre Markos was $29.7 \%$ with the commonest cause being obstructed labor and hemorrhage. The independent predictors identified were distance from the hospital, difficult labor and antenatal care utilization. The overall proportion of MNM in Amhara regional referral hospitals was 23.3\% and determinant factors including no formal education, hospital stay more than 7 days, not booked,adminsrative factors and medical personnel factors which were significantly had association with maternal miss $[7,17]$.

In other study done in Addis Ababa public hospitals on magnitude and associated factors on maternal near miss cases and showed that the most types of near miss events were under diagnostic categories of preeclampsia (36.1\%) followed by incomplete abortion(1.9\%), antepartum hemorrhage in $18.3 \%$ of cases and uterine rupture(1.2\%)[18]. This study aimed to assess delay of maternal near miss (MNM) and associated factors among women in Felege Hiwot Comprehensive Specialized Hospital (FHCSH), Northwest Ethiopia.

\section{Methods}

\section{Study design}

Hospital based cross sectional study was conducted among women who visited FHCSH for obstetric and pregnancy related gynecologic services.

\section{Study setting}

The study was conducted from May 1, 2018 to September 30, 2018 at FHCSH in Bahir Dar Amhara Regional state, North West, Ethiopia. Bahir Dar is the capital city of Amhara National Regional State, located $565 \mathrm{~km}$ Northwest of Addis Ababa with an altitude of 1799 meters above sea level. It has an estimated population of 348,429 as per 2017 world population review. FHCSH is one of the governmental hospitals in Amhara regional state with estimated catchment population of seven millions and has 8 cluster primary hospitals and 4 health centers in Bahir Dar.The hospital serves for more than $5,000,000$ populations in its catchment area and it has one big maternity ward which possesses around 74 beds. There are about 6000 deliveries per year, $30 \%$ of which is cesarean deliveries. There are 9 obstetricians, 36 residents and 25 midwives currently working in the department of obstetrics and gynecology. As it is a referral hospital most of the clients are referral cases from health centers and district hospitals.

\section{Study population}


Women who were diagnosed to have MNM case as per modified WHO criteria from were included.

\section{Study variables}

\section{Dependent variables}

Delay in maternal near miss

\section{Independent variables}

Residence, distance to hospital, educational status of the mother and husband, occupation, transport access, number of ANC visit, awareness on obstetric complication, monthly income

\section{Sample size determination}

Sample size was determined assumptions using single population proportional formula considering $95 \%$ confidence interval and proportion of critically ill obstetric patients among total termination of pregnancy[7]. Hence, $287 \mathrm{MNM}$ cases were included for this study.

\section{Operational definition}

Maternal near miss: is any women admitted and managed as a case of maternal near miss as modified near miss criteria for sub Saharan African countries[19].

First delay: is a delay at home before deciding to the first health facility which will be defined as the number of hours between the onset of labor or complication and decision to go to the first health facility with accepted time not more than 24 hours.

Second delay: delay in reaching the first health facility which is the number of hours between leaving and reaching health facility with accepted time set being not more than 1 hour.

Third delay: delay within the health facility which can be divided in two phases as

(a).1st phase corresponds to the period between arrival at the 1st health facility and arrival at the last health facility with accepted time not more than 1 hour.

(b).The second phases corresponded to the time spent between arrival at the final hospital and evaluation and care given which is accepted as not more than 30 minute.

Any delay: delay was considered if a woman experienced any of the delays [15]. 


\section{Data collection and procedure}

The medical document of the women who were managed as a case of maternal near miss over a study period and the patient was used to collect data at time discharge from all wards. Using structured check list and questionnaire, information on their sociodemography, booking status, clinical features at presentation and the place of attempt to get emergency obstetric care were extracted by the data collectors both from their documents and patients with questionnaires. Modified WHO criteria on maternal near miss for sub Saharan African countries was used to identify MNM cases. Data on the intraoperative findings, treatment, associated complications and maternal outcomes were also collected. Check list was checked by supervisors on daily basis for completeness.

\section{Data quality control}

Prior to data collection, the check list was tested to check the consistency of the checklist format and the ability of the data collector's performance. The checklist and questionnaire were modified based on the pretest results. One-day training on how to carry out data collection and quality control was given for the data collectors.

\section{Data processing and analysis}

Data was entered in to Epi Info 7 and then transported to SPSS 23 software packages for analysis. Descriptive statistics such as mean, percentage and standard deviation, were determined. To identify the correlates of MNM cases by the three delays types, binary logistic regression was conducted. The $p$ value of 0.05 levels was chosen as the level of significance and 95\% confidence interval (Cl). Covariate having $p$ value of less than 0.25 was taken to multivariate analysis and statically significance was described with adjusted odd ratio. The results were described using tables.

\section{Results}

\section{Socio Demographic Characteristics}

There were 2694 patients who came to FHCSH for pregnancy related complaints including delivery, abortion post-delivery complications and postabortal complications management. From all the admitted cases 287 women was managed as MNM with modified WHO criteria.

The mean age of mothers with maternal near miss was $29.6 \pm 6.8$ years with majority in 25-34 range accounting about $48.4 \%$. About $36 \%$ of delay was identified in those with $25-34$ years. The proportion of maternal near miss was $10.65 \%$. 
Most MNM cases were from rural area with $58.9 \%$ and $83.6 \%$ of them were Orthodox by religion. About $95 \%$ were married and $67.7 \%$ of them were outside $10 \mathrm{Kms}$ distance from FHCSH. $56.3 \%$ of maternal near miss mothers did not attend a formal education while $43.7 \%$ had formal education. $50 \%$ of them were famers by occupation while the remaining were employee, housewife and merchants in decreasing order respectively. The family monthly income was found to be above the mean (3265) in $63.1 \%$ of the cases and the remaining were below the mean monthly income calculated (Table 1).

\section{Obstetric parameters and delay}

The frequency distribution of gravidity showed that $33.8 \%$ of them were Primigravida and 29.3 were grand multiparous and $81.9 \%$ of them had singleton followed by ruptured ectopic pregnancy, gestational trophoblastic disease and twin pregnancy with 7.7\%, 5.2 and $5.2 \%$ in decreasing order. The majority of maternal near miss had ANC follow up in $73 \%$ of the cases with $80 \%$ of them had 3 and above visits. Ninety two percent of maternal near miss cases were referred and $55 \%$ of referral was from health center followed by primary hospital (30.5\%) and private institution (14.3\%). $21.3 \%$ of maternal near miss were double referral from health center to primary hospital to FHCSH. Eclampsia (16.4\%), postpartum hemorrhage (11.8\%) and obstructed labor (11.5\%) were the major diagnosis made at admission in FHCSH.The mean duration of hospital stay was $9.49 \pm 3.73$ days with $54 \%$ of them stay $7-14$ days. From all the maternal near miss $69 \%$ had already near miss at admission and 15.7 of them had near miss within 24 hours and after 24 of admission for both. From all MNM cases studied $44 \%$ of them had delay one and $35 \%$ had delay two while $51 \%$ of them had delay three. Only $26 \%$ of MNM cases did not have any form of delay (Table 2).

\section{Factors affecting delay of maternal near miss}

All factors that were tested with binary logistic regression and were statically significant with $p$ value of 0.25 and below were;place of residence, distance from home to $\mathrm{FHCSH}$,educational status of the husband,educational status of the mother,occupation,number of ANC visits,lack of awareness on obstetric complications, lack of transport and monthly family income. The mentioned covariate were tested with any delay as dependent variable using multivariable logistic regression using back ward conditional method and as it is depicted in table 7 rural residence is 3.2 times had association with any delay with $p$ value of 0.001 and AOR of (1.6-6.37) and those who are living in area which is $10 \mathrm{Kms}$ away from FHCSH were 2 times more likely to have delay with $p$ value of 0.025 and AOR of 2.18(1.14.29). Those mothers who had difficulty in accessing transport were 3.9 times more likely to have delay as compared with no difficulty with $p$ value of 0.009 and AOR 3.9(1.4-10.8).From all MNM cases those that had lack of awareness on obstetric complication were more likely to have delay $33.5 p$ times as compared to that were aware of possible obstetric complication with $p$ value of 0.001 and AOR of 33.5(4.59-246.1)(Table 3). 


\section{Discussion}

The proportion of MNM in this study was $10.65 \%$. The proportion is low as compared to the study in Egypt (19\%) and Nigeria (12\%).The difference might be due to the difference in set up and the timing of the research which was 3-4 years back as compared to the study. The proportion of MNM in Amhara referral hospitals was $23.3 \%$ which was higher than this study. The possible reason in this wide difference could be due to wide expansion of district hospital in every wereda for the last 4 years that deceases the absolute number of MNM cases. The incidence of MNM worldwide ranges from 0.6 and $14.98 \%$ and in low resource income countries $4 \%$ which shows the result in this study is high. The MNM mortality ratio and mortality index (MI) in Jimma were $5.8: 1$ and $14.8 \%$ respectively while in this study MNM mortality ratio and mortality index were 31.9: 1 and 3\% respectively. The discrepancy might be due to high catchment area of Jimma hospital and high number of district hospitals in Bahir Dar $[5,6,15,17$, 20-23].

The commonest obstetric complications identified as a cause of maternal near miss in our study were sepsis (37\%), hypertensive disorders of pregnancy including eclampsia and preeclampsia with severity features $(24.8 \%)$ followed by obstructed labor, uterine rupture and postpartum hemorrhage accounting $14.3 \%, 11.8 \%$ and $11.5 \%$ of maternal near miss respectively. Ruptured ectopic pregnancy and complicated abortion accounted $9.8 \%$ and $6.4 \%$ of maternal near miss cases.

As it is shown different literature in Africa, India,Pakistan and particularly in Ethiopia the commonest obstetric complications that causes MNM were hypertensive disorders of pregnancy, obstetric hemorrhage and sepsis.But in our study the leading causes were sepsis and hypertensive disorders of pregnancy specifically eclampsia.This is possibly due to the majority of MNM in our study were having delay $74 \%$ and the presence of many primary hospital that refer patients after a long stay at their facility. Additionally, complicated abortion and ruptured ectopic pregnancy contributed for MNM cases which are higher than the other studies except Zambian study. The possible reason is likely due to delayed in diagnosis and referral to FHCSH for majority of ruptured ectopic pregnancies by primary hospitals and health centers. The contribution of complicated abortion, obstructed labor and sepsis for MNM cases in Ethiopian setting is higher $[6,7,14,17,18,20-22,24-26]$.

In MNM cases studied $91.6 \%$ of the patients were referred from health institutions which the majority being from health centers in $55.3 \%$ and followed by primary hospitals and private institution accounting $30.5 \%$ and $14.3 \%$ respectively. The majority of maternal near misses were pregnant at time of referral in $38.4 \%$ and intrapartum in $35.5 \%$ of cases. From all the referred cases of MNM $70 \%$ of them first visited health centers and there were $21 \%$ MNM cases with double referral.

In the five-month study period from all MNM cases analyzed $44.3 \%$ of them had delay 1 with mostly mentioned reason were lack of awareness on obstetric complications in $40.2 \%$, belief in alternative care or traditional or natural remedies in $19.5 \%$ and thinking no need to seek medical care in $13.6 \%$ of the MNM cases. Around $35 \%$ of MNM cases studied had delay model 2 which the commonest reason 
mentioned were lack of ambulance in $84.8 \%$ and lack of finance in $10.1 \%$ of the cases. From all MNM cases $51.2 \%$ had delay 3 and $74.2 \%$ of them had more than one delay.

Researches done in Latin America, South Africa and Egypt showed that MNM cases are associated with any delay which is comparable to our result with contribution from every phase of delay but the contribution in delay 1 and delay 2 were higher in Ethiopia due to the fact that low socio economic status, in accessible ambulance and low infrastructure in our catchment area specifically and the region at large but there is no study in Ethiopia done on delay of MNM cases $[13,14]$.

In our study bivariable logistic regression analysis showed the determinant factors for delayed obstetric care for MNM were place of residence, distance from home to FHCSH,educational status of the husband,educational status of the mother,occupation,number of ANC visits,lack of awareness on obstetric complications, lack of transport and monthly family income and from this listed factors multivariable analysis showed the statically significant association with delay in mothers with MNM were rural residence (AOR 3.2(1.6-637,p value of 0.001)),distance more than $10 \mathrm{Km}$ radius away from FHCSH(AOR 2.18(1.1-4.29,p value 0.025)).lack of ambulance (AOR,3.9 (1.4-10.8),p value of $0.0009)$ )and lack of awareness on obstetric complications (AOR,33.5 $p$ value of 0.001$)$ ).

In a study done in done in Women's Health Hospital, Assiut University Egypt showed that significantly associated factors with delay pattern identified in the study were financial problems, fear of maltreatment in health institutions, lack of awareness about obstetric complications, lack of antenatal care, lack of participation in decision making, negative attitude for health professionals and lack of blood with $p$ value of $<0.05$ for all factors which is not similar with current finding due to the fact the set up in Egypt and timing of the research which was 4 years back[15].

The other study on barriers to obstetric care in MNM cases showed that delay was identified in $83 \%$ of MNM cases which slightly higher than this study (76\%).Phase I and phase III delays were the commonest whereas all the delay contributed to delay in MNM. The difference might be due to the difference in setting. The commonest factors for delay were lack of knowledge of problems, in adequate ANC and delay in admission, referral and treatment [14].

The other study in Ethiopia on delay in utilizing institutional delivery showed that maternal unemployment $(A O R=2.5)$, husband educational status $(A O R=2.3)$ antenatal care visit $(A O R=0.4)$ were the determinant factors for delay 1 and for delay 2, distance (AOR, 14) and transportation $(A O R, 0.6)$ with $p$ value of $<0.05$ for all factors which is similar only in distance and transport issues which is due to almost similar distribution of health institution in Amhara and SNNs. The other possible reason is that it was only those mothers who needed delivery service that were studied in the above [27-29].

\section{Limitation of the study}


Patient information related with transportation, duration of stay at home and referring health institutions were collected retrospectively which might lead to recall bias. This study was conducted in a single health facility.

\section{Conclusion}

The proportion of MNM cases in FHCSH is still high. Majority of them had delay irrespective of delay models due to lack of ambulance, long distance from home to FHCSH, rural residence and low understanding of the obstetric complications during pregnancy.

\section{Abbreviations}

AOR Adjusted odd ratio

FHCSH Felege Hiwot Compressive Specialized Hospital

HELLPHemolysis elevated liver enzymes and low platelet count

ICU Intensive care unit

MNM Maternal near miss

MVA Manual vacuum aspiration

SVD Spontaneous vaginal delivery

WHO World Health Organization

\section{Declarations}

\section{Ethics and consent to participate}

Ethical approval was asked and approved from the institutional review board of college of medicine and health sciences Bahir Dar University. Since it had no more than minimal risk of harm to the participants and did not involve procedures on participants, verbal consent was taken from patients if they can communicate or from their attendants if they were critically ill. Confidentiality was maintained when handling each case files and patient herself. All the participants included were above the age of 16 years.

\section{Consent to publish}

Not applicable. 


\section{Availability of data and Materials}

All data generated or analyzed during this study are available from the corresponding author on reasonable request.

\section{Competing interests}

The authors declare that they have no competing interests.

\section{Funding}

Not applicable

\section{Authors' Contributions}

AW- had contributed in conception, design, analysis \& interpretation of data, drafted and wrote the manuscript. EW- has been involved in the design of the study and revising the manuscript. GDContributed on study design, analysis \& interpretation of data, and reviewed the manuscript. All authors have participated sufficiently in this study and approved the final manuscript.

\section{Acknowledgements}

We are grateful to all the women and their attendants participated in study.

\section{References}

1.Government of India Ministry of Health and Family Welfare: maternal near miss review Operational Guidelines. In:

.2014.

2.World Health Organization: Evaluating the quality of care for severe pregnancy complications: the WHO near-miss approach for maternal health. 2011.

3.Say L, Souza JP, Pattinson RC: Maternal near miss-towards a standard tool for monitoring quality of maternal health care. Best practice \& research Clinical obstetrics \& gynaecology 2009, 23(3):287-296.

4.Kushwah B, Singh A, Natung P: Analysis of various criteria for identification of severe acute maternal morbidity in a rural tertiary health care centre: A prospective one year study. Int J Med Sci Public Health 2014, 3:330-334. 
5.Tunçalp Ö, Hindin MJ, Souza J, Chou D, Say L: The prevalence of maternal near miss: a systematic review. BJOG: An International Journal of Obstetrics \& Gynaecology 2012, 119(6):653-661.

6.Abdel-Raheem SS, Mahran DG, Al-Attar GS, Qayed MH, Zareh ZE, Othman EE-DR: Magnitude and pattern of maternal near-miss cases admitted to Women's Health Hospital, Assiut University. Journal of Current Medical Research and Practice 2016, 1(3):92.

7.Dile M, Seyum T: Proportion of maternal near misses and associated factors in referral hospitals of Amhara regional state, Northwest Ethiopia: institution based cross sectional study. Gynecol Obstet (Sunnyvale) 2015, 5(308):2161-0932.1000.

8.World Health Organization: Trends in maternal mortality: 1990-2015: estimates from WHO, UNICEF, UNFPA, World Bank Group and the United Nations Population Division: executive summary. In.: World Health Organization; 2015.

9.EDHS ED: Health Survey. Key indicators report 2016.

10.Tessema GA, Laurence CO, Melaku YA, Misganaw A, Woldie SA, Hiruye A, Amare AT, Lakew Y, Zeleke BM, Deribew A: Trends and causes of maternal mortality in Ethiopia during 1990-2013: findings from the Global Burden of Diseases study 2013. BMC public health 2017, 17(1):160.

11.Kassebaum NJ, Barber RM, Bhutta ZA, Dandona L, Gething PW, Hay SI, Kinfu Y, Larson HJ, Liang X, Lim SS: Global, regional, and national levels of maternal mortality, 1990-2015: a systematic analysis for the Global Burden of Disease Study 2015. The Lancet 2016, 388(10053):1775-1812.

12.Pacagnella RC, Cecatti JG, Osis MJ, Souza JP: The role of delays in severe maternal morbidity and mortality: expanding the conceptual framework. Reproductive health matters 2012, 20(39):155-163.

13.Pacagnella RC, Cecatti JG, Parpinelli MA, Sousa MH, Haddad SM, Costa ML, Souza JP, Pattinson RC: Delays in receiving obstetric care and poor maternal outcomes: results from a national multicentre crosssectional study. BMC pregnancy and childbirth 2014, 14(1):159.

14.Soma-Pillay P, Pattinson RC: Barriers to obstetric care among maternal near-misses. South African Medical Journal 2016, 106(11):1110-1113.

15.Abdel-Raheem SS, Al-Attar GS, Mahran DG, Qayed MH, Alib Z-AZ, Othman EE-DR: Delays associated with maternal near-miss cases admitted in Women's Health Hospital, Assiut University. Journal of Current Medical Research and Practice 2017, 2(1):1.

16.David E, Machungo F, Zanconato G, Cavaliere E, Fiosse S, Sululu C, Chiluvane B, Bergström S: Maternal near miss and maternal deaths in Mozambique: a cross-sectional, region-wide study of 635 consecutive cases assisted in health facilities of Maputo province. BMC Pregnancy and Childbirth 2014, 14(1):401. 
17.Gedefaw M, Gebrehana H, Gizachew A, Taddess F: Assessment of maternal near miss at Debre Markos referral hospital, Northwest Ethiopia: five years experience. Open Journal of Epidemiology 2014, 4(04):199.

18.Liyew EF, Yalew AW, Afework MF, Essén B: Incidence and causes of maternal near-miss in selected hospitals of Addis Ababa, Ethiopia. PloS one 2017, 12(6):e0179013.

19.Tura AK, Stekelenburg J, Scherjon SA, Zwart J, van den Akker T, van Roosmalen J, Gordijn SJ: Adaptation of the WHO maternal near miss tool for use in sub-Saharan Africa: an International Delphi study. BMC pregnancy and childbirth 2017, 17(1):445.

20.Adeoye IA, Onayade AA, Fatusi AO: Incidence, determinants and perinatal outcomes of near miss maternal morbidity in Ile-Ife Nigeria: a prospective case control study. BMC pregnancy and childbirth 2013, 13(1):93.

21.Samarina Kamal1* PR, Shashibala Singh3, Jacinta Minz3 A study of maternal near miss cases at tertiary medical college of Jharkhand, India International Journal of Reproduction, Contraception, Obstetrics and Gynecology April 2017

22. Woldeyes WS, Asefa D, Muleta G: Incidence and determinants of severe maternal outcome in Jimma University teaching hospital, south-West Ethiopia: a prospective cross-sectional study. BMC pregnancy and childbirth 2018, 18(1):255.

23.Goldenberg RL, Saleem S, Ali S, Moore JL, Lokangako A, Tshefu A, Mwenechanya M, Chomba E, Garces A, Figueroa L: Maternal near miss in low-resource areas. International Journal of Gynecology \& Obstetrics 2017, 138(3):347-355.

24.Kalisa R, Rulisa S, van den Akker T, van Roosmalen J: Maternal near miss and quality of care in a rural Rwandan hospital. BMC pregnancy and childbirth 2016, 16(1):324.

25.Mazhar SB, Batool A, Emanuel A, Khan AT, Bhutta S: Severe maternal outcomes and their predictors among Pakistani women in the WHO Multicountry Survey on Maternal and Newborn Health. International Journal of Gynecology \& Obstetrics 2015, 129(1):30-33.

26.Liyew EF, Yalew AW, Afework MF, Essén B: Distant and proximate factors associated with maternal near-miss: a nested case-control study in selected public hospitals of Addis Ababa, Ethiopia. BMC women's health 2018, 18(1):28.

27.Gazala Yasmin1* RN, Shahreyar Ghazi2, Astha Lalwani1 Maternal near miss events: a prospective observational study in a tertiary care centre International Journal of Reproduction, Contraception, Obstetrics and Gynecology

28.Sibley L, Amare Y: Illness recognition and care seeking for maternal complications of pregnancy and birth in rural Amhara and Oromia Regional States of Ethiopia. BMC pregnancy and childbirth 2017, 
29.Lire A, Beyamo A, Tadele D, Facha W: Delays for utilizing institutional delivery and associated factors among mothers attending public health facility in Hadiya Zone, Southern Ethiopia. Science 2017, 5(6):149-157.

\section{Tables}

Table 1: socio-demographic characteristics of mothers who had MNM at FHCSH October, 2018

\begin{tabular}{|c|c|c|c|}
\hline \multicolumn{2}{|l|}{ Socio- demographic characteristics } & \multirow{2}{*}{\begin{tabular}{|l|} 
Frequency \\
74 \\
\end{tabular}} & \multirow{2}{*}{$\begin{array}{l}\text { Percent (\%) } \\
25.8 \\
\end{array}$} \\
\hline Age in years & $17-24$ & & \\
\hline & $25-34$ & 139 & 48.4 \\
\hline & $35-45$ & 74 & 25.8 \\
\hline \multirow[t]{4}{*}{ Religion } & Orthodox & 240 & 83.6 \\
\hline & Muslim & 36 & 12.5 \\
\hline & Protestant & 10 & 3.5 \\
\hline & Catholic & 1 & 0.3 \\
\hline \multirow[t]{3}{*}{ Marital status } & Married & 273 & 95.1 \\
\hline & Single & 10 & 3.5 \\
\hline & Divorced & 4 & 1.4 \\
\hline \multirow[t]{2}{*}{ Current residency } & Urban & 118 & 41.1 \\
\hline & Rural & 169 & 58.9 \\
\hline \multirow[t]{2}{*}{ Distance from home to FHCSH } & Less than $10 \mathrm{Kms}$ & 93 & 32.4 \\
\hline & Greater than $10 \mathrm{Kms}$ & 194 & 67.6 \\
\hline \multirow[t]{5}{*}{ Ethnicity } & Amhara & 278 & 96.9 \\
\hline & Oromo & 1 & 0.3 \\
\hline & Tigray & 4 & 1.4 \\
\hline & SNNs & 1 & 0.3 \\
\hline & Benshangul Gumuz & 3 & 1 \\
\hline \multirow[t]{5}{*}{ Educational status of MNM cases } & Can't read and write & 133 & 46.3 \\
\hline & Can read and write & 29 & 10.1 \\
\hline & Primary school & 42 & 14.6 \\
\hline & high school & 34 & 11.8 \\
\hline & College and above & 49 & 17.1 \\
\hline \multirow[t]{5}{*}{ Educational status of the husband } & Can't read and write & 100 & 34.8 \\
\hline & Can read and write & 42 & 14.6 \\
\hline & Primary school & 43 & 15 \\
\hline & high school & 36 & 12.5 \\
\hline & College and above & 56 & 19.5 \\
\hline \multirow[t]{4}{*}{ Occupation } & Housewife & 48 & 16.7 \\
\hline & Farmer & 145 & 50.5 \\
\hline & Employee & 74 & 25.8 \\
\hline & Merchant & 20 & 7 \\
\hline \multirow[t]{2}{*}{ Monthly income of family in Ethiopian birr } & $<3265$ & 181 & 63.1 \\
\hline & $>=3265$ & 106 & 36.9 \\
\hline
\end{tabular}


Table 2: Obstetric characteristics of mothers, who had MNM at FHCSH October, 2018 


\begin{tabular}{|c|c|c|c|}
\hline \multicolumn{2}{|l|}{ Past obstetric characteristics } & Frequency & Percent \\
\hline \multirow[t]{3}{*}{ Gravidity } & 1 & 97 & 33.8 \\
\hline & $2-4$ & 106 & 36.9 \\
\hline & $>=5$ & 84 & 29.3 \\
\hline \multirow[t]{3}{*}{ Parity } & 0 & 106 & 36.9 \\
\hline & $1-4$ & 110 & 38.3 \\
\hline & $>=5$ & 71 & 24.7 \\
\hline \multirow[t]{4}{*}{ Type of gestation currently } & Ectopic pregnancy & 22 & 7.7 \\
\hline & GTD & 15 & 5.2 \\
\hline & Singleton & 235 & 81.9 \\
\hline & Twin & 15 & 5.2 \\
\hline \multirow[t]{4}{*}{ GA of current pregnancy } & $<28$ wks. & 71 & 24.7 \\
\hline & 28-37 wks. & 36 & 12.5 \\
\hline & $>37$ wks. & 140 & 48.8 \\
\hline & Unknown & 40 & 13.9 \\
\hline \multirow[t]{2}{*}{ ANC status } & Has ANC & 209 & 72.8 \\
\hline & No ANC & 78 & 27.2 \\
\hline \multirow[t]{4}{*}{ Number ANC visits } & 1 & 11 & 5.2 \\
\hline & 2 & 34 & 16.2 \\
\hline & 3 & 80 & 38.1 \\
\hline & 4 and above & 85 & 40.5 \\
\hline \multirow[t]{2}{*}{ Referred before admission } & Yes & 263 & 91.6 \\
\hline & No & 24 & 8.4 \\
\hline \multirow[t]{3}{*}{ Place of referral } & Health center & 147 & 55.3 \\
\hline & Primary hospital & 81 & 30.5 \\
\hline & Private institution & 38 & 14.3 \\
\hline \multirow[t]{3}{*}{ Referral timing } & Antepartum & 104 & 38.4 \\
\hline & Intrapartum & 95 & 35.1 \\
\hline & After termination & 72 & 26.6 \\
\hline \multirow[t]{4}{*}{ First visited institution } & Health center & 202 & 70.4 \\
\hline & \begin{tabular}{|l|} 
Primary hospital \\
\end{tabular} & 41 & 14.3 \\
\hline & Private institution & 30 & 10.5 \\
\hline & FHCSH & 14 & 4.9 \\
\hline \multirow[t]{9}{*}{ Diagnosis at FHCSH } & Uterine rupture & 33 & 11.5 \\
\hline & Ruptured ectopic pregnancy & 28 & 9.8 \\
\hline & GTD with complication & 17 & 5.9 \\
\hline & $\begin{array}{l}\text { Preeclampsia with severity } \\
\text { feature }\end{array}$ & 24 & 8.4 \\
\hline & Eclampsia & 47 & 16.4 \\
\hline & Obstructed labor & 41 & 14.3 \\
\hline & $\mathrm{PPH}$ & 34 & 11.8 \\
\hline & Complicated abortion & 23 & 8 \\
\hline & Others & 40 & 13.9 \\
\hline \multirow{3}{*}{$\begin{array}{l}\text { Time interval between admission and near } \\
\text { miss }\end{array}$} & At admission & 197 & 68.6 \\
\hline & \begin{tabular}{|l} 
Within 24 hours \\
\end{tabular} & 45 & 15.7 \\
\hline & After 24 hours & 45 & 15.7 \\
\hline \multirow[t]{2}{*}{ Duration of hospital stay } & 1-7 days & 109 & 38 \\
\hline & 8-14 days & 154 & 53.7 \\
\hline
\end{tabular}




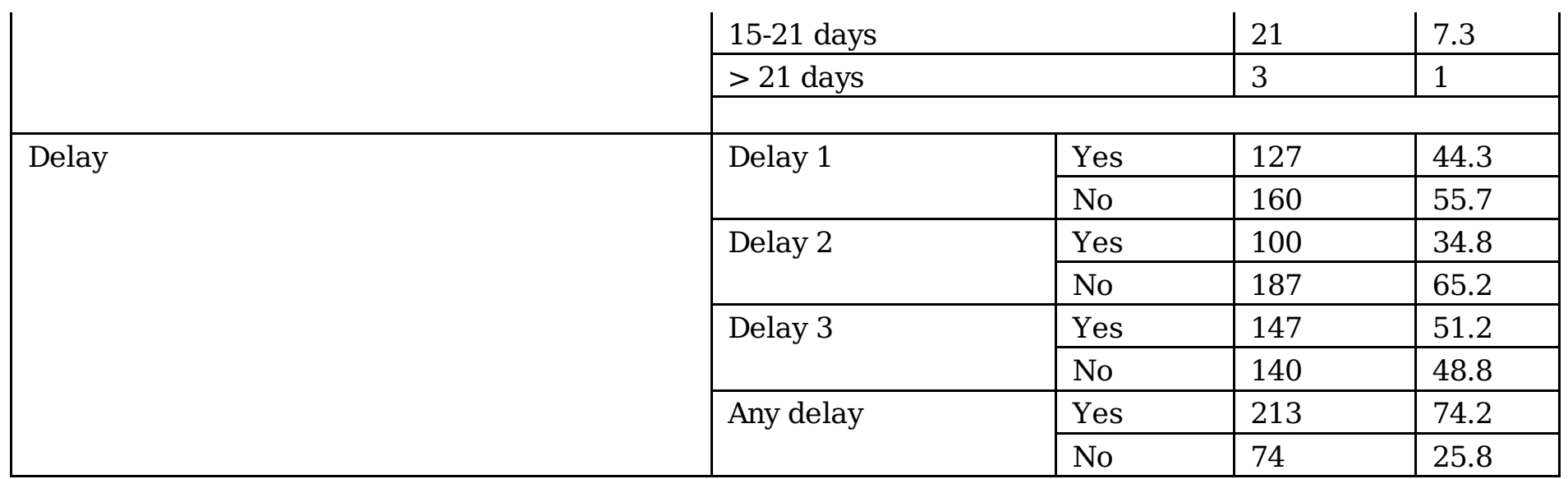

Table 3: Binary and multivariable logistic regression for factors associated with delay in MNM cases in FHCSH, 2018. 


\begin{tabular}{|c|c|c|c|c|c|}
\hline Variables & & $\mathrm{COR}$ & p-value & $\mathrm{AOR}$ & $\begin{array}{l}\mathrm{P}- \\
\text { value }\end{array}$ \\
\hline \multirow[t]{2}{*}{ Residence } & Urban & 1 & & 1 & \\
\hline & Rural & $\begin{array}{l}5.75(3.21- \\
10.30)\end{array}$ & $<0.0001$ & $\begin{array}{l}3.20(1.61- \\
6.37)\end{array}$ & $0.001 *$ \\
\hline \multirow[t]{2}{*}{ Distance from home to hospital } & $<10 \mathrm{~km}$ & 1 & & 1 & \\
\hline & $>10 \mathrm{~km}$ & $4.52(2.58-7.92)$ & $<0.0001$ & $\begin{array}{l}2.18(1.1- \\
4.29)\end{array}$ & $0.025^{*}$ \\
\hline \multirow[t]{6}{*}{ Educational status of the mother } & & & $<0.0001$ & & \\
\hline & Illiterate & $\begin{array}{l}2.17(0.81- \\
5.86)\end{array}$ & 0.0125 & & \\
\hline & Read and write & $2.13(0.9-5.11)$ & 0.089 & & \\
\hline & Primary school & $\begin{array}{l}6.07(2.61- \\
14.11)\end{array}$ & $<0.0001$ & & \\
\hline & High school & $\begin{array}{l}2.17(3.07- \\
13.96)\end{array}$ & 0.125 & & \\
\hline & $\begin{array}{l}\text { College and } \\
\text { above }\end{array}$ & 1 & & & \\
\hline \multirow[t]{6}{*}{ Educational status of the husband } & & & $<0.0001$ & & \\
\hline & Illiterate & $\begin{array}{l}2.45(0.92- \\
6.57) 2\end{array}$ & 0.074 & & \\
\hline & $\begin{array}{l}\text { Can read and } \\
\text { write }\end{array}$ & $3.48(1.37-8.86)$ & 0.009 & & \\
\hline & Primary school & $5.73(2.25-14.6)$ & 0.000 & & \\
\hline & High school & $\begin{array}{l}6.75(2.91- \\
15.65)\end{array}$ & 0.074 & & \\
\hline & $\begin{array}{l}\text { College and } \\
\text { above }\end{array}$ & 1 & & & \\
\hline \multirow[t]{5}{*}{ Occupation } & & & $<0.0001$ & & \\
\hline & Employee & 1 & & & \\
\hline & Farmer & $\begin{array}{l}0.34(0.16- \\
0.76)\end{array}$ & 0.009 & & \\
\hline & Housewife & $2.30(1.1-4.98)$ & 0.034 & & \\
\hline & Merchant & $\begin{array}{l}1.04(0.33- \\
3.26)\end{array}$ & 0.945 & & \\
\hline \multirow[t]{2}{*}{ Lack of transport } & Yes & $\begin{array}{l}5.67(2.18- \\
14.72)\end{array}$ & $<0.0001$ & $\begin{array}{l}3.90(1.41- \\
10.83)\end{array}$ & $0.009 *$ \\
\hline & No & 1 & & 1 & \\
\hline \multirow[t]{3}{*}{ Number of ANC } & $<4$ visits & $\begin{array}{r}2.42(1.3- \\
4.49) .005\end{array}$ & 0.005 & & \\
\hline & $\begin{array}{l}4 \text { and above } \\
\text { visits }\end{array}$ & 1 & & & \\
\hline & No & 1 & & 1 & \\
\hline \multirow[t]{2}{*}{$\begin{array}{l}\text { Lack of awareness on obstetric } \\
\text { complication }\end{array}$} & Yes & $\begin{array}{l}33.5(4.59- \\
246.16)\end{array}$ & 0.001 & $\begin{array}{l}\text { 27.93(3.7- } \\
210.68)\end{array}$ & $\begin{array}{l}0.001 * \\
*\end{array}$ \\
\hline & No & 1 & & 1 & \\
\hline Monthly income & $\begin{array}{l}1 .<3265 \text { birr } \\
2 .>3265 \text { birr }\end{array}$ & $\begin{array}{l}2.43(1.42-4.17) \\
1\end{array}$ & 0.001 & & \\
\hline
\end{tabular}

*-statistically significant 


\section{Supplementary Files}

This is a list of supplementary files associated with this preprint. Click to download.

- additionalfile1.docx 